\title{
Transurethral resection of the prostate with preservation of the bladder neck decreases postoperative retrograde ejaculation
}

\author{
Jie Liao ${ }^{1}$, Xiaobo Zhang ${ }^{1,2,3}$, Mingquan Chen ${ }^{1}$, Dongjie $\mathrm{Li}^{2}$, Xinji Tan ${ }^{1}$, Jie $\mathrm{Gu}^{1}$, Sheng $\mathrm{Hu}^{1}, \mathrm{Xiong} \mathrm{Chen}^{1,2,3}$ \\ ${ }^{1}$ Department of Geriatric Medicine, Xiang Ya Hospital, Central South University, Changsha, China \\ ${ }^{2}$ International Medical Center, Xiang Ya Hospital, Central South University, Changsha, China \\ ${ }^{3}$ National Clinical Research Center for Geriatric Disorders, Xiang Ya Hospital, Central South University, Changsha, China
}

Videosurgery Miniinv 2019; 14 (1): 96-101

DOI: https://doi.org/10.5114/wiitm.2018.79536

\begin{abstract}
Introduction: Even though transurethral resection of the prostate (TURP) is the standard surgical treatment for benign prostatic hyperplasia (BPH), there is a high rate of postoperative retrograde ejaculation.

Aim: To evaluate the effectiveness of TURP with preservation of the bladder neck in comparison with that of standard TURP.

Material and methods: This is a retrospective study. 137 men with BPH were divided into two groups: TURP with preservation of the bladder neck and standard TURP were performed respectively in group $A$ and group $B$. The patients were evaluated preoperatively and at 3, 6 and 12 months after surgery by International Prostate Symptom Score (IPSS), health-related quality of life (HRQL) score, maximum urinary flow rate (Qmax), postvoid residual urine volume (PVR) and the rate of complications including retrograde ejaculation.

Results: There was no statistically significant difference between groups in terms of the operative duration, catheterization period, hemoglobin decrease, and hospital stay. At the 3-month follow-up, the rates of incontinence and retrograde ejaculation in group A were lower than those in group B. At the 6-and 12-month follow-ups, the difference in the frequency of retrograde ejaculation remained constantly stable whereas the incontinence rates were similar in both groups. The IPSS, HRQL score, Qmax, PVR and the rate of complications including hematuria, clot retention, urinary tract infection, urethral stricture, and bladder neck contracture evaluated at 3, 6 and 12 months also displayed a very similar response in the two groups.

Conclusions: Comparable with standard TURP, TURP with preservation of the bladder neck appears to provide a satisfactory clinical outcome in decreasing early postoperative incontinence and lowering the rate of retrograde ejaculation.
\end{abstract}

Key words: benign prostatic hyperplasia, transurethral resection of the prostate, bladder neck preservation, retrograde ejaculation, incontinence.

\section{Introduction}

Benign prostatic hyperplasia (BPH), as the most common disease in male urological pathology [1], represents a serious public health problem in our contemporary society. Although it is benign, this disease has been shown to have a negative impact on the patient's health-related quality of life (HRQL), marked by obstructive and irritative lower urinary tract symptoms (LUTS) [2, 3]. Despite continuing development of new minimally invasive surgical methods, transurethral resection of the prostate (TURP) still remains the gold standard surgical treatment for LUTS due to BPH $[4,5]$, with more than $90 \%$ of the

Address for correspondence

Xiong Chen, Department of Geriatric Medicine, International Medical Center, National Clinical Research Center for Geriatric Disorders,

Xiang Ya Hospital, Central South University, 78 Xiangya Road, 410008 Changsha, China, phone: +86 13574187264,

e-mail: chenxiong@csu.edu.cn 
patients reporting normal or improved urinary voiding over the 10-year follow-up period. TURP has undergone significant improvements in the last decade [6]. The key point of standard TURP is resecting the tissues enveloped in the prostatic capsule and the bladder neck, while protecting the urethral tissues below the verumontanum $[7,8]$. To achieve an improved bladder outlet, circumferential overresection of the bladder neck has been performed, which is commonly thought to cause excessive hemorrhage, uncontrolled perforation of the bladder, prostatic capsule or prostatovesical junction during the operation, as well as sexual dysfunction and bladder neck contracture in the long-term follow-up $[9,10]$.

\section{Aim}

We aim to evaluate the safety and efficiency of TURP with preservation of the bladder neck and compare it with the conventional standard TURP.

\section{Material and methods}

This study was approved by the Local Ethics and Research Committee. Patients in Xiang Ya Hospital with the diagnosis of BPH between January 2013 and January 2016 were included in the assessment.

Inclusion criteria: The International Prostate Symptom Score (IPSS) > 19 after the medical therapy failure. Written informed consent was obtained from the patients. The exclusion criteria were detrusor hypocontractility or overactivity on urodynamic study, untreated acute urinary retention, incontinence, urethral stricture, retrograde ejaculation (which was confirmed by testing the urine for the presence of sperm after a dry ejaculation), prostate cancer, previous prostate, bladder neck or urethral surgery and metabolic (including diabetes mellitus) disorders and neurologic disorders. The patients with the value of prostate-specific antigen (PSA) $>2.5 \mathrm{ng} / \mathrm{ml}$ or abnormal digital rectal examination findings underwent prior ultrasound-guided prostate biopsy. A total of 137 patients with a mean age of 66 years (ranging from 53 to 81) were included in the study and they were divided into group $A$ ( $n=58$, TURP with bladder neck preservation) and group B ( $n=79$, conventional standard TURP).

General clinical examination including blood tests, PSA level measurement, digital rectal examination (DRE), urine culture, IPSS, HRQL, maximum urinary flow rate (Qmax) and postvoid residual urine volume (PVR) was applied in all cases. All patients received spinal anaesthesia and the same surgeon performed all the operations.

Conventional TURP was done as described previously [11]. The TURP with preservation of the bladder neck was performed as follows: in order to retain tissues in the bladder neck, resection started from $0.5 \mathrm{~cm}$ to $0.8 \mathrm{~cm}$ away from the bladder neck, while the rest of the procedures were comparable with those of the standard TURP. In the case of the lobes that highly proliferate or protrude into the bladder, operations aiming at removing those prostate tissues that broke into the bladder and that highly proliferate around the bladder neck were performed, avoiding any injury to the muscle fibers in the bladder neck. Both procedures were carried out using a $27 \mathrm{~F}$ continuous-flow resectoscope (Richard Wolf, Germany) with an irrigating fluid containing glycine $1.5 \%$. A ValleyLab Forcex electrosurgical unit was used for cutting and coagulation ( $80 \mathrm{~W}$ and $120 \mathrm{~W}$ ).

Patients were evaluated at a follow-up time of 1 year. The 3-, 6- and 12-month follow-ups assessed the PSA level measurement, IPSS, HRQL, Qmax, PVR and rates of complications (including urethral stricture, incontinence, bladder neck contracture, and retrograde ejaculation) in all patients, which were compared between the groups.

\section{Statistical analysis}

Student's $t$-test and the $\chi^{2}$ test were used for statistical analysis of the data, with $P<0.05$ considered to indicate statistical significance.

\section{Results}

Table I shows the clinical characteristics of the patients before surgery, which were similar between the two groups. In addition, there was no significant difference in the operative time, catheterization time, hemoglobin decrease or hospital stay between the two groups (Table II). As shown in Table III, at 3-, 6- and 12-month follow-ups, improvements in all the measured variables were similar in the two groups.

Table IV shows operative, early (<60 days) and late ( $>60$ days) complications. Between the two groups, there was no significant difference in the rates of all measured operative and early complications which include hematuria plus transfusion, 
Table I. Baseline characteristics

\begin{tabular}{|lccc|}
\hline Parameter & Group A, mean (SD) & Group B, mean (SD) & $P$-value \\
\hline$N$ & 58 & 79 & 0.706 \\
\hline Age [years] & $67.5(8.52)$ & $66.7(10.27)$ & 0.321 \\
\hline Prostate volume $\left[\mathrm{cm}^{3}\right]$ & $51.9(12.21)$ & $54.5(11.81)$ & 0.284 \\
\hline PAS $[\mathrm{ng} / \mathrm{ml}]$ & $2.56(1.37)$ & $2.23(1.30)$ & 0.785 \\
\hline PVR $[\mathrm{ml}]$ & $97.5(24.7)$ & $99.3(33.3)$ & 0.115 \\
\hline Qmax $[\mathrm{ml} / \mathrm{s}]$ & $6.72(2.6)$ & $7.9(3.66)$ & 0.407 \\
\hline IPSS & $21.5(3.26)$ & $20.9(2.6)$ & 0.444 \\
\hline HRQL & $5.0(0.89)$ & $4.9(0.85)$ & \\
\hline
\end{tabular}

Table II. Perioperative results

\begin{tabular}{|lccc|}
\hline Parameter & Group A, mean (SD) & Group B, mean (SD) & $P$-value \\
\hline Operative time [min] & $60.1(12.81)$ & $58.0(11.19)$ & 0.454 \\
\hline Catheterization time $[\mathrm{h}]$ & $84.6(30.86)$ & $93.6(27.2)$ & 0.17 \\
\hline Hemoglobin decrease $[\mathrm{g} / \mathrm{dl}]$ & $1.2(1.18)$ & $1.4(1)$ & 0.555 \\
\hline Hospital stay [days] & $7.4(2.06)$ & $6.6(1.85)$ & 0.091 \\
\hline
\end{tabular}

Table III. Results at 3-, 6- and 12- months follow-ups

\begin{tabular}{|c|c|c|c|}
\hline Parameter & Group A, mean (SD) & Group B, mean (SD) & $P$-value \\
\hline \multicolumn{4}{|l|}{ IPSS: } \\
\hline 3 months & $10.1(4.54)$ & $9.1(4.36)$ & 0.343 \\
\hline 6 months & $9.8(4.48)$ & $9.1(3.97)$ & 0.462 \\
\hline 12 months & $9.0(4.02)$ & $9.2(4.04)$ & 0.782 \\
\hline \multicolumn{4}{|l|}{ HRQL: } \\
\hline 3 months & $2.4(1.67)$ & $2.2(1.94)$ & 0.712 \\
\hline 6 months & $2.1(1.80)$ & $2.5(2.03)$ & 0.354 \\
\hline 12 months & $2.0(1.40)$ & $2.1(1.85)$ & 0.838 \\
\hline \multicolumn{4}{|l|}{ Qmax $[\mathrm{ml} / \mathrm{s}]:$} \\
\hline 3 months & $19.5(3.34)$ & $19.8(3.87)$ & 0.735 \\
\hline 6 months & $20.8(3.37)$ & $21.4(3.84)$ & 0.469 \\
\hline 12 months & $21.4(3.91)$ & $21.4(4.34)$ & 0.981 \\
\hline \multicolumn{4}{|l|}{ PVR [ml]: } \\
\hline 3 months & $17.9(5.69)$ & $20.3(5.87)$ & 0.069 \\
\hline 6 months & $18.7(6.46)$ & $17.3(7.25)$ & 0.373 \\
\hline 12 months & $17.0(7.53)$ & $18.8(6.51)$ & 0.237 \\
\hline \multicolumn{4}{|c|}{ Prostate volume [ml]: } \\
\hline 3 months & $18.9(3.81)$ & $17.8(4.50)$ & 0.274 \\
\hline 6 months & $19.1(4.55)$ & $18.1(4.07)$ & 0.284 \\
\hline 12 months & $19.5(3.56)$ & $18.3(4.04)$ & 0.159 \\
\hline
\end{tabular}


Table IV. Complications

\begin{tabular}{|c|c|c|c|}
\hline Complications & Group A, $n(\%)$ & Group B, $n(\%)$ & $P$-value \\
\hline \multicolumn{4}{|l|}{ Intraoperative: } \\
\hline Hematuria plus transfusion & $4(6.9)$ & $4(5.1)$ & 0.651 \\
\hline Mild hyponatremia & $0(0)$ & $1(1.3)$ & 1 \\
\hline \multicolumn{4}{|l|}{ Early: } \\
\hline Hematuria & $6(10.3)$ & $10(12.6)$ & 0.677 \\
\hline Clot retention & $3(5.2)$ & $3(3.8)$ & 0.698 \\
\hline Urinary tract infection & $2(3.4)$ & $2(2.5)$ & 0.753 \\
\hline \multicolumn{4}{|l|}{ Late: } \\
\hline \multicolumn{4}{|l|}{ Urethral stricture: } \\
\hline 3 months & $1(1.7)$ & $0(0)$ & 0.241 \\
\hline 6 months & $1(1.7)$ & $0(0)$ & 0.241 \\
\hline 12 months & $1(1.7)$ & $1(1.3)$ & 0.825 \\
\hline \multicolumn{4}{|l|}{ Incontinence: } \\
\hline 3 months & $1(6.9)$ & $9(11.4)$ & 0.032 \\
\hline 6 months & $0(0)$ & $3(3.8)$ & 0.133 \\
\hline 12 months & $0(0)$ & $1(1.3)$ & 0.390 \\
\hline \multicolumn{4}{|l|}{ Bladder neck contracture: } \\
\hline 3 months & $0(0)$ & $1(1.3)$ & 0.390 \\
\hline 6 months & $2(3.4)$ & $1(1.3)$ & 0.388 \\
\hline 12 months & $2(3.4)$ & $1(1.3)$ & 0.388 \\
\hline \multicolumn{4}{|l|}{ Retrograde ejaculation: } \\
\hline 3 months & $34(58.6)$ & $69(87.3)$ & $<0.001$ \\
\hline 6 months & $19(32.8)$ & $61(77.2)$ & $<0.001$ \\
\hline 12 months & $19(32.8)$ & $59(74.7)$ & $<0.001$ \\
\hline
\end{tabular}

mild hyponatremia, hematuria, clot retention and urinary tract infection. At the 3-month follow-up, the rates of incontinence and retrograde ejaculation in group A were lower than those in group B. The difference in the frequency of retrograde ejaculation remained constantly stable in all regards at the 6- and 12-month follow-ups, though the 6- and 12-month evaluation of the rates of incontinence were similar in both groups. The rates of other late complications including urethral stricture and bladder neck contracture evaluated at 3, 6 and 12 months also displayed a very similar response in the two groups.

\section{Discussion}

A competent ring of smooth muscle at the bladder neck in the male has been described [12]. The bladder neck is a part of the bladder base with a laminar architecture, and it is combined with the deep deltoid layer [13]. A muscle layer deep in the superficial layer is connected with the detrusor. The smaller muscle bundles of the deep muscle layer in the bladder base show a predominantly circular orientation. The importance of the bladder neck as the main part of maintaining continence still remains controversial $[14,15]$. The bladder neck plays a sig- 
nificant role in reproduction. For men, bladder neck closure facilitates anterograde ejaculation. It actively contracts the bladder neck during ejaculation through a rich noradrenergic innervation by sympathetic nerves [16]. In our study, TURP with preservation of the bladder neck was performed and the results of this technique were compared with those of standard TURP. There was no significant difference between the two groups in terms of the operative duration, catheterization period, hemoglobin decrease, hospital stay, IPSS, HRQL, Qmax, PVR and the rate of hematuria, clot retention, bladder neck contracture and urethral stricture.

One of the complications of TURP is postoperative retrograde ejaculation, which accounts for not only male infertility but also impaired sexual satisfaction [17]. The rate of retrograde ejaculation after TURP approximated $70-90 \%[18,19]$. The internal urethral sphincter (smooth sphincter of the bladder neck) is regarded as an indispensable part of the "compression chamber", delimited anteriorly by the external sphincter of the urethra (striated sphincter), in which the seminal fluid accumulates and resides when it reaches the prostatic urethra before being expelled during ejaculation. Therefore, retrograde ejaculation was considered a physiological result of the removal of the smooth sphincter of the bladder neck $[19,20]$. Another alternative treatment option for BPH is transurethral incision of the prostate (TUIP), which has been proved to be an effective treatment option decreasing the rate of retrograde ejaculation, but the weaknesses of TUIP were reported to be the insufficiency in reducing prostate volume at the median lobe hyperplasia and the inability to obtain specimens for pathology so that the incidental prostate cancer cannot be diagnosed [21]. During TURP, we emphasize the protection of the bladder neck, especially the muscle fibers in it. At the 3-, 6- and 12-month follow-ups, the rates of retrograde ejaculation were lower in group $A$ than those in group B: they were $58.6 \%$ vs. $87.3 \%, 32.8 \%$ vs. $77.2 \%$, and $32.8 \%$ vs. $74.7 \%$ respectively (all $p<0.05)$. This result can be interpreted as an effect of the preservation of the bladder neck, which has prevented seminal fluid from going back into the bladder during ejaculation.

Early incontinence can occur in up to $30-40 \%$ of patients, while late iatrogenic stress incontinence occurs in fewer than $0.5 \%$ of patients, due to an incomplete external urethral sphincter. Early incontinence usually urges symptomatic or irritative symptoms such as associated urinary tract infection (UTI) and fossa healing or detrusor instability caused by long-lasting BPH [22, 23]. In this study, at the 3-month follow-up, the rate of incontinence in group A was lower, $6.9 \%$ vs. $11.4 \%(p<0.05)$, while at the 12-month follow-up there was no patient with incontinence in either group. A decreasing trend of the rate in the standard TURP group was observed, which is in accordance with previous reports [11]. The low rate of early incontinence in patients undergoing TURP with preservation of the bladder neck in our study may be due to less damage of the prostate or detrusor instability by preserving the bladder neck. Moreover, postoperative bladder neck contracture was seen in $1(2.5 \%)$ patient in the standard TURP group and $2(5 \%)$ patients in the TURP with preservation of the bladder neck group, but the difference was not significant.

\section{Conclusions}

Comparable with standard TURP, TURP with preservation of the bladder neck appears to provide a satisfactory clinical outcome in decreasing early postoperative incontinence and lowering the rate of retrograde ejaculation. However, both follow-up time and the number of cases may not be sufficient to draw strong conclusions from this study.

\section{Conflict of interest}

The authors declare no conflict of interest.

\section{References}

1. Berry SJ, Coffey DS, Walsh PC, et al. The development of human benign prostatic hyperplasia with age. J Urol 1984; 132: 474-9.

2. Zhu BS, Jiang HC, Li Y. Impact of urethral catheterization on uroflow during pressure-flow study. J Int Med Res 2016; 44: 1034-9.

3. Unnikrishnan R, Almassi N, Fareed K. Benign prostatic hyperplasia: evaluation and medical management in primary care. Cleve Clin J Med 2017; 84: 53-64.

4. Peng M, Yi L, Wang Y. Photoselective vaporization of the prostate vs plasmakinetic resection of the prostate: a randomized prospective trial with 12-month follow-up in mainland China. Urology 2016; 87: 161-5.

5. Zhang X, Zeng X, Dong L, et al. The effects of statins on benign prostatic hyperplasia in elderly patients with metabolic syndrome. World J Urol 2015; 33: 2071-7.

6. Long Z, Zhang YC, He LY, et al. Comparison of transurethral plasmakinetic and transvesical prostatectomy in treatment of 100-149 mL benign prostatic hyperplasia. Asian J Surg 2014; 37 : 58-64. 
7. Thomas AW, Cannon A, Bartlett E, et al. The natural history of lower urinary tract dysfunction in men: minimum 10-year urodynamic followup of transurethral resection of prostate for bladder outlet obstruction. J Urol 2005; 174: 1887-91.

8. Marszalek M, Ponholzer A, Rauchenwald M, et al. Palliative transurethral resection of the prostate: functional outcome and impact on survival. BJU INT 2007; 99: 56-9.

9. Coulthard MG. Adult and Pediatric Urology. Mosby Year Book 1996.

10. Yeni E, Unal D, Verit A, et al. Minimal transurethral prostatectomy plus bladder neck incision versus standard transurethral prostatectomy in patients with benign prostatic hyperplasia: a randomised prospective study. Urol Int 2002; 69: 283-6.

11. Rassweiler J, Teber D, Kuntz R, et al. Complications of transurethral resection of the prostate (TURP): incidence, management, and prevention. Eur Urol 2006; 50: 969-79.

12. Gosling JA, Dixon JS, Jen PY. The distribution of noradrenergic nerves in the human lower urinary tract. A review. Eur Urol 1999; 36 Suppl 1: 23-30.

13. Asimakopoulos AD, Mugnier C, Hoepffner IL, et al. Bladder neck preservation during minimally invasive radical prostatectomy: a standardised technique using a lateral approach. BJU Int 2012; 110: 1566-71.

14. Nyarangi-Dix JN, Radtke JP, Hadaschik B, et al. Impact of complete bladder neck preservation on urinary continence, quality of life and surgical margins after radical prostatectomy: a randomized, controlled, single blind trial. J Urol 2013; 189: 891-8.

15. Giannarini G, Manassero F, Mogorovich A, et al. Cold-knife incision of anastomotic strictures after radical retropubic prostatectomy with bladder neck preservation: efficacy and impact on urinary continence status. Eur Urol 2008; 54: 647-56.

16. He LY, Zhang YC, He JL, et al. The effect of immediate surgical bipolar plasmakinetic transurethral resection of the prostate on prostatic hyperplasia with acute urinary retention. Asian J Androl 2016; 18: 134-9.

17. Walsh, Patrick C. Campbell's Urology. W.B. Saunders Co. 2002.

18. Barazani Y, Stahl PJ, Nagler HM, et al. Management of ejaculatory disorders in infertile men. Asian J Androl 2012; 14: 525-9.

19. Gil-Vernet JJ, Alvarez-Vijande R, Gil-Vernet A, et al. Ejaculation in men: a dynamic endorectal ultrasonographical study. $\mathrm{Br}$ J Urol 1994; 73: 442-8.

20. Ronzoni G, De Vecchis M. Preservation of anterograde ejaculation after transurethral resection of both the prostate and bladder neck. Br J Urol 1998; 81: 830-3.

21. Lourenco T, Shaw M, Fraser C, et al. The clinical effectiveness of transurethral incision of the prostate: a systematic review of randomised controlled trials. World J Urol 2010; 28: 23-32.

22. Zwergel U. [Benign prostatic hyperplasia (BPH) syndrome. Surgical and interventional therapy options]. Urologe A 2001; 40: 319-329.

23. Bartoletti R, Mogorovich A, Francesca F, et al. Combined bladder neck preservation and posterior musculofascial reconstruction during robotic assisted radical prostatectomy: effects on early and long term urinary continence recovery. BMC Urol 2017; 17: 119.

Received: 23.04.2018, accepted: 7.10.2018. 